\title{
Integrated Planning of A Large-scale Heat Pump In View of Heat and Power Networks
}

\author{
Klyapovskiy, Sergey; You, Shi; Cai, Hanmin; Bindner, Henrik W.
}

Published in:

IEEE Transactions on Industry Applications

Link to article, DOI:

10.1109/TIA.2018.2864114

Publication date:

2018

Document Version

Peer reviewed version

Link back to DTU Orbit

Citation (APA):

Klyapovskiy, S., You, S., Cai, H., \& Bindner, H. W. (2018). Integrated Planning of A Large-scale Heat Pump In View of Heat and Power Networks. IEEE Transactions on Industry Applications, 55(1), 5 - 15.

https://doi.org/10.1109/TIA.2018.2864114

\section{General rights}

Copyright and moral rights for the publications made accessible in the public portal are retained by the authors and/or other copyright owners and it is a condition of accessing publications that users recognise and abide by the legal requirements associated with these rights.

- Users may download and print one copy of any publication from the public portal for the purpose of private study or research.

- You may not further distribute the material or use it for any profit-making activity or commercial gain

- You may freely distribute the URL identifying the publication in the public portal

If you believe that this document breaches copyright please contact us providing details, and we will remove access to the work immediately and investigate your claim. 


\title{
Integrated Planning of A Large-scale Heat Pump In View of Heat and Power Networks
}

\author{
Sergey Klyapovskiy, Shi You, Hanmin Cai, Henrik W. Bindner Center for Electric Power and Energy (CEE) \\ Technical University of Denmark (DTU) \\ 2800 Kgs. Lyngby, Denmark \\ Email: seklya@elektro.dtu.dk
}

\begin{abstract}
With the present trend towards smart grid and integrated energy systems, the potential benefits achieved by developing integrated planning and operation solutions crossing multiple energy sectors become recently recognizable. This paper investigates the problem of optimal planning for a large-scale heat pump (HP) - a component that links electric and heat utilities together, from an integrated perspective. The proposed method assures an optimal system design with the minimum expense on both capital expenditure (CAPEX) and operating expense (OPEX) for the heat network and the electrical network, given that the optional HP locations are already provided together with other technical and economic information needed for executing the planning exercise. The operational flexibility of the HP, i.e., the ability of reducing its electricity consumption from time to time, is also integrated into the planning method. The value of the proposed solution is demonstrated throughout a case study that resembles a live planning exercise conducted for a green field area in Denmark.
\end{abstract}

Index Terms-Flexibility, heat pump, integrated energy system, integrated planning, heat and power networks

\section{INTRODUCTION}

The increased focus on the efficiency in the energy sectors and $\mathrm{CO} 2$ emission reduction in the recent years bring attention toward an integrated energy system (IES) [1], [2]. IES is the system comprising of multiple energy sectors, such as electricity, heat, transportation and gas. Ideally, an IES can be optimized for a performance as a whole system using synergies between the sectors for the common benefits at both planning and operation stages [3], [4].

The integration between electricity sector and heat sector has been recently recognized as a prominent example for creating add-on values for both sectors, enabled by the fact that the two sectors have been loosely interconnected for many years through a variety of technologies, such as combined heat and power generation (CHP), electric heat pump (HP) and boiler [5], [6]. Together with the significant energy storage potential in the heat sector, the value of these electric heating solutions have been widely demonstrated to address challenges such as power balancing [7] and congestion management [8] in the electricity sector and to facilitate the development of the heat sector towards a better system, e.g. the 4th generation of district heating $(\mathrm{DH})$ [9].

Among several technologies that can transform electrical power to heat, HP is the one that draws the most of attention due to its supreme operational characteristics and potential benefits it could bring to the system [10]. In countries like
Denmark with widespread use of DH systems and CHPs, using large-scale $\mathrm{HP}$ for $\mathrm{DH}$ can supplement or even to certain level replace the existing DH solution [11]. In early 2018, Denmark is set to support 13 large HP projects with DKK23m (\$3.7m) in funding [12]. To ensure the deployment of HPs can result in a maximum societal benefit, i.e., the total benefit achieved by the involved stakeholders in different energy sectors, developing optimal planning solutions from an integrated perspective is significantly necessary.

At present, the common practice of large-scale HP planning is an exercise that involves a limited degree of collaboration between the two energy bodies, i.e., the district heating operator (DHO) and the electricity distribution grid operator (DSO). This exercise is often initiated by the DHO who produces a plan for sitting and sizing of the HP with little consideration of its impacts on the electrical network, and followed by the DSO who provides a connection plan with little influence on the heat system planning. An early work conducted in [13] investigated this issue by proposing an integrated planning method, and demonstrated its value in achieving a more economic solutions when the two bodies work collaboratively.

This paper extends the method proposed in [13] by giving much more elaboration on the integrated planning method and by including the flexibility potential (i.e., the ability of the HP reducing its electricity consumption from time to time) into the integrated optimal planning. Provided all relevant information is accessible, the proposed method assures an optimal system design with the minimum expense on both capital expenditure (CAPEX) and operating expense (OPEX) for the heat network and the electrical network.

The validity of the proposed solution is demonstrated throughout a case study that resembles a live planning exercise conducted for an urban green field area in Denmark. A largescale HP, as the single heat source for this area, is to be deployed to meet the end users heat demand through a heat network with an optimal layout. Several potential locations are already provided, and each location has a preferable HP technology that can take the best use of the local energy resources. Electrically, the HP will be connected to an existing $10 \mathrm{kV}$ distribution network which offers a number of optional connection points.

Paper is organized as follows. The methodology for studying the problem is given in sections II-V and presented on the flowchart on Fig. 1. Section II provides the general explanation of how the different calculation parts of the flowchart are 


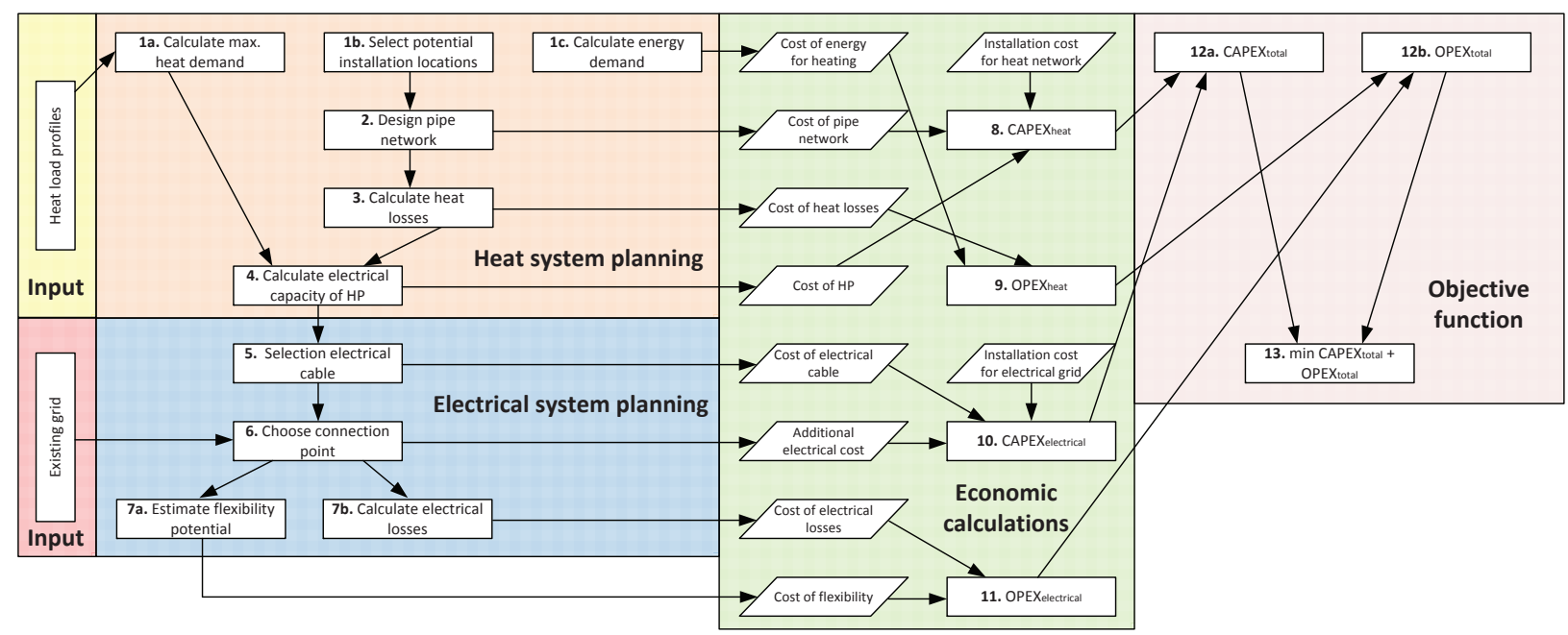

Fig. 1: Flowchart showing the methodology used for heat system planning, electrical system planning, economic calculations and final objective function

performed. Sections III, IV describe the methodology used for heat and electrical network planning respectively, with Section $\mathrm{V}$ explaining the calculations of the economical parameters. The case study is presented in Section VI, with results given in Section VII. Finally, conclusions are drawn in Section VIII.

\section{GeNERAL DESCRIPTION}

The flowchart showing the proposed methodology is given on Fig. 1.

The problem solved by this study is about optimal sitting and sizing of a large HP in a view of integrated energy networks. In practice, the number of scenarios that has to be considered is not high because of the constraining factors like landscape, availability of different kinds of heat sources and the economy.

The problem is formulated as a trilevel optimization. First level is the heat system planning. It is formulated as a linear integer optimization with the connectivity and pipe sizes as decision variables. The lookup table is used to check for the pressure constraint. Only CAPEX cost is considered on that stage.

Electrical system planning represents a second level. It is a linear integer optimization that is solved by brute force search due to the limited number of scenarios. The decision variables are the size of electrical cables and the connection point to the existing electrical grid. The constraints are the voltage and maximum apparent power, that are checked after the best solution is found. Similar to the first level, only CAPEX of the electric utility is considered.

The third level is an optimization of both CAPEX and OPEX for both utilities combined, which is solved by brute force.

\section{Heat system Planning}

This section describes the methodology concerning heat system planning used in studying this problem.
To successfully execute the project of supplying heating to the city district via HP, DHO needs to estimate the heat demand, evaluate and select several potential locations for HP installation, determine the pipe network configuration, pipe lengths and diameters and calculate the heat losses. After all these parameters are obtained, the electrical capacity needed to run a HP can be identified. The methodology for acquiring all these parameters is shown in the subsection.

\section{A. Estimation of heat demand}

Typical city district mainly consists of buidings belonging to either residential or commercial (office) customer categories, which could be characterised among other things by their demand for space heating (SP) and domestic hot water (DHW). Fig. 2 shows the example of monthly energy demand to provide SP and DHW to an apartment block in Copenhagen (data is extrapolated from [14]). Energy demand profiles for other building types show similar trend with high demand in the fall and winter months and with low demand in spring and summer. This is mainly due to the changes in the SP needs, while DHW demand can be considered almost constant throughout the year. The exact amount of required energy for SP depends on a climate, insulation type and building location (sunny side or not, etc.) [15].

If HP is assumed to be the only source of heat for the urban district, its capacity should be able to fully cover the peak heat demand plus heat losses. Using the historic time-series data of the heat demand for the buildings of similar type as should be supplied allows to forecast the peak heat demand with good precision. However, such data may not always be available, so monthly averaged heat demand shown on Fig. 2 can be used instead. The peak-to-average ratio is used to estimate the peak value for each month.

Diversity factor $D F$ is used to take into account, that not all of the buildings require heat at any given time. 


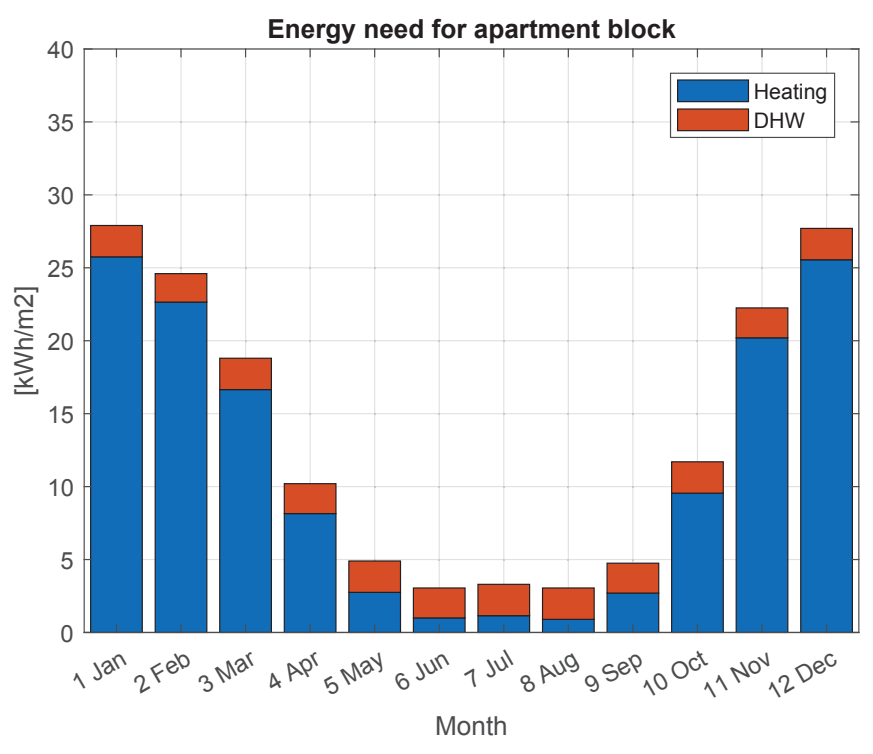

Fig. 2: Example of monthly energy demand for SP and DHW for an apartment block in Copenhagen

The forecasted peak demand for the heat load is then calculated as follows:

$$
Q_{\text {heat } \text { peak }}=\max \left\{D F \sum_{i=1}^{n} \sum_{j=1}^{r} N_{j} S_{j} \frac{E_{i j}}{H_{i}} P T A_{i j}\right\},
$$

where $Q_{\text {heat }}$ peak - peak demand, [W]; $D F$ - diversity factor; $i$ - month, $n$ - number of months with available data; $j$ - building type, $r$ - number of building types; $N$ - number of buildings of certain type, $S$ - size of a heated area for a specific building type, $\left[\mathrm{m}^{2}\right] ; E$ - average monthly heat demand, $\left[\mathrm{Wh} / \mathrm{m}^{2}\right] ; H$ number of hours in each month; PTA - peak-to-average ratio.

The amount of energy DHO should provide during a year:

$$
E_{\text {heat,year }}=\sum_{i=1}^{n} D F \sum_{j=1}^{r} N_{j} S_{j} E_{i j},
$$

where $E_{\text {heat,year }}$ - total energy required for heating, [Wh].

\section{B. Selecting installation location of $H P$}

The locations for installing HP are traditionally determined by DHO after comprehensive technico-economic analysis. One of the main factor is the availability of the heat source (groundwater, seawater, air, exhaust heat, etc.), which could be easily extracted without the need for expensive engineering procedures. Due to the high building density in the urban areas, finding an available place that is large enough for installation and respecting all the safety regulations is another concern. Third desired criteria is the proximity to the heat customers to decrease the total length of the pipe network. Combining these three factors together result in a very limited number of possible locations for HP installation.

In this paper, the installation location is considered to affect coefficient of performance (COP) of HP, due to the different heat source utilized at each spot. It will also influence the heat losses, which are dependant on pipe network length among other factors as will be shown below.

\section{Designing DH pipe network}

Design pipe network for DH represents an optimization (minimization) problem with several parameters that have to be determined. First, the pipe network layout have to be established, which determines how to connect HP with customers. After this, the flow rate is calculated and used to select appropriate pipes diameter to be able to supply the peak heat demand from Eq. 1. The goal is to achieve the least cost solution, while satisfying the constraint for allowable pressure drop [16]. The decision variables are length and diameter of the pipes. The optimization problem can be expressed as follows:

$$
\begin{array}{cl}
\min & \sum C_{\text {pipe,ft }}=f\left(l_{\text {pipe,ft }}, d_{\text {pipe,ft }}\right), \\
\text { s.t. } & \Delta P r \leq \Delta P r_{\max },
\end{array}
$$

where $C_{\text {pipe }}$ - cost of the pipe, [\$]; $f, t$ - from and to nodes of the heating network respectively; $l_{\text {pipe }}$ - length of the pipe, $[m] ; d_{\text {pipe }}$ - pipe inner diameter, $[\mathrm{m}] ; \Delta P r$ - pressure drop, $[\mathrm{Pa} / \mathrm{m}] ; \Delta \mathrm{Pr}_{\max }$ - maximum allowable pressure drop, $[\mathrm{Pa} / \mathrm{m}]$.

The pipe diameter is selected according to the volume of the water flow $V_{\max }$ that should go through it. $V_{\max }$ can be calculated as shown below [16]:

$$
V_{\text {flow }, \text { max }_{k}}=\frac{Q_{\text {pipe, peak }_{k}}}{c_{p} \rho\left(T_{\text {supply }}-T_{\text {return }}\right)},
$$

where $V_{\text {flow, } \max }$ - volume of the water flow, $\left[\mathrm{m}^{3} / \mathrm{s}\right] ; k$ pipe number; $Q_{\text {pipe,peak }}$ - peak demand for a particular pipe, calculated using Eq. 1. $[W] ; c_{p}$ - heat capacity of water, $[\mathrm{J} / \mathrm{kgK}] ; \rho$ - density of water, $\left[\mathrm{kg} / \mathrm{m}^{3}\right] ; T_{\text {supply }}, T_{\text {return }}$ - average supply and return temperature respectively, $\left[{ }^{\circ} \mathrm{C}\right]$.

\section{Calculation of the heat losses}

Heat losses is an important parameter that will affect HP OPEX and influence the amount of required electric power HP is using. Heat losses are dependant on the supply and return temperatures of the water, the temperature of the surroundings around the pipe, the pipe's material, length and diameter. To estimate annual heat losses Eq. 6 is used [17]:

$$
E_{\text {heat }, \text { loss,year }}=2 \pi D_{a} L_{\text {pipe }} K \cdot G,
$$

where $E_{\text {heat,loss,year }}$ - annual heat losses, $[W h] ; D_{a}$ - average inner diameter of the pipes in the network, $[m] ; L$ - network route length of the pipe system, $[\mathrm{m}] ; K$ - average heat transmission coefficient, $\left[\mathrm{W} / \mathrm{m}^{2} \mathrm{~K}\right] ; G$ - coefficient showing annual integration of the average distribution temperature difference, $\left[{ }^{\circ} \mathrm{Ch}\right]$.

Average pipe inner diameter $D_{a}$ is calculated:

$$
D_{a}=\frac{\sum_{k=1}^{p} d_{\text {pipe }, k}}{p},
$$

where $p$ - total number of pipes. 
Network route length $L$ :

$$
L_{\text {pipe }}=\sum_{k=1}^{p} l_{\text {pipe, }},
$$

Average heat transmission coefficient $K$ depends on the insulation materials of the pipes and their inner diameter. Typically higher values of $K$ correspond to the high-quality pipes. $K$ for the whole network lies in the following range:

$$
0.1088 \cdot D_{a}^{-0.619} \leq K \leq 0.7676 \cdot D_{a}^{-0.341},
$$

Coefficient $G$ :

$$
G=\frac{1}{2}\left(\left(T_{\text {supply }}+T_{\text {return }}\right)-T_{\text {surround }}\right) \cdot h_{\text {heat }},
$$

where $T_{\text {surround }}$ - average surroundings temperature, $\left[{ }^{\circ} \mathrm{C}\right]$; $h_{\text {heat }}$ - number of heating hours in a year, $[h]$.

Relative losses $q_{\text {loss,relative }}$ are used as an average estimation of the heat losses, that occur at any certain point in time:

$$
q_{\text {loss, relative }}=\frac{1}{\left(1+\frac{E_{\text {heat } y \text { sear }}}{E_{\text {heat } \text { loss,yar }}}\right)} \cdot 100 \text {, }
$$

where $q_{\text {loss,relative }}$ - relative heat losses.

\section{E. Determining electrical capacity of $H P$}

Knowing the forecasted maximum heat demand $Q_{\text {heat,peak }}$ and relative heat losses $q_{\text {loss,relative, the required electrical }}$ capacity for running HP can be estimated using Eq. 12 [18]:

$$
P_{H P}=\frac{Q_{\text {heat }, \text { peak }} \cdot\left(1+\frac{q_{\text {loss } r \text { lative }}}{100}\right)}{C O P_{\text {avg }}},
$$

where $P_{H P}$ - electrical capacity of HP, $[W] ; C O P_{\text {avg }}$ average coefficient of performance.

COP of a HP is changing throughout the year, therefore the average COP is used to calculate the electrical capacity. Typical COP for different heat sources is: seawater - 3.59, groundwater - 3.41, air - 3.52 [19]. Different heat sources and therefore different values of $\mathrm{COP}$ are considered in the planning process.

\section{Electrical system PLANNING}

This section describes the methodology concerning electrical system planning used in studying this problem.

After $P_{H P}$ has been estimated, DSO's task is to provide the required capacity. It is done by selecting the proper electrical cable and performing power flow calculations to find a proper connection spot, that will not cause any disturbance to the nearby electrical customers and the distribution network in general.

\section{A. Selection of supplying cable}

The supplying cable will carry the power from the connection point to the HP. The full (apparent) power should be used for cable selection.

Additional reactive power required to run HP can be calculated as follows:

$$
Q_{H P}=\frac{P_{H P}}{P F} \cdot \sin (\operatorname{arcos}(P F)),
$$

where $Q_{H P}$ - reactive power needed to run HP, [VAr]; $P F$ - power factor.

The full apparent power required by HP is found according to Eq. 14 .

$$
S_{H P}=\sqrt{P_{H P}^{2}+Q_{H P}^{2}},
$$

where $S_{H P}$ - apparent power of HP, [VA].

Cable's capacity is chosen according to:

$$
S_{\text {cable,rated }} \geq S_{H P} \cdot R M,
$$

where $S_{\text {cable,rated }}$ - rated electrical capacity of cable, $[V A]$; $R M$ - reserve margin, coefficient taking into account uncertainty regarding maximum HP power consumption.

\section{B. Selection of the connection point}

Depending on the electrical capacity of HP, there could be various ways to connect it to the electrical distribution system. It could be connected to one of the already existed secondary substations (low $P_{H P}$ ), have an individual substation connected to the common feeder (medium $P_{H P}$ ) or have a dedicated direct connection from the main substation (high $P_{H P}$ ). Similar with the case of DHO heat network design, selection of the connection point for the DSO is an optimization problem:

$$
\begin{array}{cl}
\min & C_{\text {cable }, H P}+C_{\text {additional }}, \\
\text { s.t. } & V_{\text {min }} \leq V_{f} \leq V_{\text {max }}, \text { for } \forall f \\
& S_{f t} \leq S_{\text {cable,rated }}, \text { for } \forall f t
\end{array}
$$

where $C_{\text {cable }, H P}$ - cost of the cable for HP, [\$]; $C_{\text {additional }}$ - cost of additional equipment, like transformer substation or reinforced cable needed to connect HP [\$]; $V_{\min }$ and $V_{\max }$ minimal and maximum allowable voltage range, $[V] ; f, t$ from and to nodes of the electrical network respectively; $S_{f t}$ - apparent power through cable, [VA].

Cost of cable among other parameter is related to its length and cross-section:

$$
C_{\text {cable }, f t}=f\left(l_{\text {cable } f t}, J_{\text {cable }, f t}\right),
$$

where $l_{\text {cable }}$ - length of the cable, $[\mathrm{m}] ; J_{\text {cable }}$ - cable crosssection, $\left[\mathrm{mm}^{2}\right]$.

As would be explained below it is possible for DSO to reduce the additional cost for connecting HP, if flexibility services from HP could be contracted and therefore:

$$
C_{\text {additional }}=f\left(\sum_{P L=1}^{P L_{\max }} C_{f l e x i b i l i t y, y e a r, P L}\right),
$$


where $P L$ - year in the planning horizon, [year], $P L_{\max }$ - total number of years in the planning horizon, [year]; $C_{\text {flexibility,year }}$ - cost of flexibility services for one year, [\$].

\section{Power flow analysis}

In order to verify that connection of the HP does not bring any disturbance to the current customers in electrical network the power flow analysis is made. The goal is to find values of voltages and active and reactive power at each node in the system. This can be done using Newton-Raphson iterative method and Eq. 21 23 [20]:

$$
\begin{gathered}
V_{f}^{(m+1)}=\frac{\frac{P_{f t}^{s c h}-j Q_{f t}^{s c h}}{V_{f}^{*(m)}}-\sum_{t \neq f} Y_{f t} V_{t}^{(m)}}{Y_{f t}}, \\
P_{f t}^{(m+1)}=\mathbb{R}\left(V_{f}^{*(m)}\left[V_{f}^{(m)} Y_{f f}+\sum_{t=1, t \neq f} Y_{f t} V_{t}^{(m)}\right]\right), \\
Q_{f t}^{(m+1)}=-\mathbb{I}\left(V_{f}^{*(m)}\left[V_{f}^{(m)} Y_{f f}+\sum_{t=1, t \neq f} Y_{f t} V_{t}^{(m)}\right]\right),
\end{gathered}
$$

where $V_{f}$ and $V_{f}^{*}$ - complex voltage at node $\mathrm{f}$ and its complex conjugate, respectively, $[V] ; V_{t}$ - complex voltage at node t, $[V] ; m$ - iteration number; $P_{f t}^{s c h}$ and $Q_{f t}^{s c h}$ - net active $[W]$ and reactive [VAr] power, respectively; $P_{f t}$ and $Q_{f t}$ - active $[W]$ and reactive $[V A r]$ power flow through cable, respectively; $Y_{f f}$ and $Y_{f t}$ - elements of the bus admittance matrix.

The solution of the power flow equations is an iterative process, which is completed, when the difference between the current and the previous iteration is less than specified threshold. Various software programs exist for calculating the power flow, providing the network parameters and values of electrical loads are given.

Voltage $V_{f}$ in the distribution grid should respect the constraint 17 and be within the range of $0.95 \mathrm{pu}$ to $1.1 \mathrm{pu}$ [21]. Apparent power $S_{f t}$ flowing through each cable is calculated using Eq. 14 and should be in line with constraint 18 .

\section{Estimation of electrical losses}

According to [20] electrical losses at a specific time moment can be determined as follows:

$$
S_{e l, l o s s, z}=S_{f t}+S_{t f},
$$

where $S_{\text {el,loss }}$ - electrical loss, [VA]; $z$ - cable number.

Annual electrical losses:

$$
E_{e l, l o s s, y e a r}=\sum_{h=1}^{h_{e l}} \sum_{z=1} S_{e l, l o s s, z h},
$$

where $E_{\text {el,loss,year }}$ - annual electrical losses, [VA $]$ ]; $h$ - hour number; $h_{e l}$ - number of hours, when HP is supplied with power, $[h]$.

\section{ECONOMic CALCULATIONS}

This section describes the economic calculations for determining the optimal location of the HP. CAPEX represents the capital investments that are required before HP becomes operational. CAPEX include the cost of HP, cost of the installation, the cost of heat network and electrical connection. Operational costs such as electricity cost, costs of heat and electrical losses, and maintenance are included in OPEX. OPEX depends on the actual number of hours HP is operational.

\section{A. CAPEX}

Total investments are calculated according to Eq. 26

$$
C A P E X_{\text {total }}=C A P E X_{e l}+C A P E X_{\text {heat }},
$$

where CAPEX $X_{\text {total }}$ - total investments of both DSO and DHO, [\$]; CAPEX $X_{e l}$ and $C A P E X_{\text {heat }}$ - investments of electric and heating utility respectively, [\$].

$$
\begin{aligned}
& C A P E X_{e l}=C_{\text {cable }, H P}+C_{\text {additional }}+C_{e l, \text { inst }}, \\
& \text { CAPEX } X_{\text {heat }}=C_{H P}+C_{\text {heat,inst }}+\sum C_{\text {pipe }, f t},
\end{aligned}
$$

where $C_{H P}$ - cost of HP unit, [\$]; $C_{\text {el, inst }}$ and $C_{\text {heat,inst }}$ installation cost in the electrical and heat network respectively, [\$].

\section{B. OPEX}

Similar to CAPEX total operational costs consist of an electrical and heat part:

$$
O P E X_{\text {total }}=O P E X_{e l}+O P E X_{\text {heat }},
$$

where $O P E X_{\text {total }}$ - total operational costs of both DSO and DHO, [\$]; OPEX $X_{e l}$ and $O P E X_{\text {heat }}$ - operational costs of electric and heating utility respectively, [\$].

While CAPEX is the amount of investments that has to be spent immediately, OPEX represents the expenses made over the planning horizon. To be able to compare both economic indicators, the future values of OPEX are recalculated to the present values using the annuity formula:

$$
\begin{array}{r}
\text { OPEX } X_{e l}=\sum_{P L=1}^{P L_{\max }}\left(\frac{C_{\text {el,price, }, \text { vvg }, P L} \cdot E_{\text {el,loss,year }, P L}}{(1+r)^{P L}}\right. \\
\left.+\frac{C_{f l e x i b i l i t y, y e a r, P L}}{(1+r)^{P L}}\right),
\end{array}
$$

where $C_{e l, p r i c e, D S O, a v g}$ - average price for electricity for DSO, [\$]; $r$ - discount rate.

Before calculating $O P E X_{\text {heat }}$, annual heat demand and annual heat losses should be converted to electrical power values by using Eq. 31 .

$$
E_{\text {hte,year }}=\frac{E_{\text {heat }, \text { year }}}{C O P_{\text {avg }}}
$$


where $E_{\text {hte,year }}$ - energy demand converted from heat to electrical (hte), [Wh].

$$
\begin{array}{r}
\text { OPEX } X_{\text {heat }}=\sum_{P L=1}^{P L_{\max }}\left(\frac{C_{\text {el, } \text { price }, \text { HS } O, \text { avg }, P L} \cdot\left(E_{\text {hte, year }, P L}\right.}{(1+r)^{P L}}\right. \\
\left.+\frac{E_{\text {hte,loss,year }, P L}}{(1+r)^{P L}}\right),
\end{array}
$$
[\$].

where $C_{e l, p r i c e, D S O, \text { avg }}$ - average price for electricity for HSO,

\section{Estimating the cost of flexibility}

As was mentioned in the introduction, the reason to move towards IES is the potential synergies between various energy sectors. In case the additional cost for connection the HP to electrical network $C_{\text {additional }}$ becomes very high, due to the need to reinforce the main cable, build or expand a secondary substation, DSO could try to contract the DR services from this HP. Such services will mainly include peak reduction or load shifting during the peak demand hours of the electrical distribution system [22]. By incorporating the smart control of HP, monitoring customers indoor temperature and using methods for demand anticipation, DR services for electrical grid could be provided without compromising the heat customers comfort levels. In addition to that, it is assumed that DHO installs heat storage tank together with the source of DH [23]-[25].

The cost of using flexibility services from HP is difficult to establish due to the uncertainty in the amount of services that would be needed. One of the way to estimate the cost is using Eq. 33 .

$$
C_{\text {flexibility,year }}=\left(\sum_{T=1}^{T_{\max }} P_{\text {reduction,avg, } T} \cdot D_{T} \cdot C_{\text {avg }, T}\right)+C_{\text {frequency }} \text {, }
$$

where $\mathrm{T}$ - period of using flexibility (period consists of consecutive hours) within one year; $T_{\max }$ - maximum number of periods; $P_{\text {reduction,avg, } T}$ - average peak reduction during period T, $[W] ; D_{T}$ - duration of a period T, $[h] ; C_{a v g, T}$ average price for the period $\mathrm{T}, C_{\text {avg, } T}=f\left(P_{\text {reduction, avg }, T}, D_{T}\right)$, [\$]; $C_{\text {frequency }}$ - additional cost, depending on how often the flexibility services were used, $C_{\text {frequency }}=f\left(T_{\max }\right)$, [\$].

To estimate the cost of flexibility, DSO should identify the periods $T$, when such services could be required and the amount of power $P_{\text {reduction }}$, that have to be reduced. The concept is shown on Fig. 3

To be able to build the demand curves depicted on Fig. 3 . a reliable forecast based on historical data from the area is required. The cost for each period depends on the amount of power reduced, period's duration and the time of day when the service is activated. To simplify the calculations, the average values are used in Eq. 33 .

\section{Objective function}

In the IES the interest of all stakeholders need to be taken into consideration. In case of integrated electric and

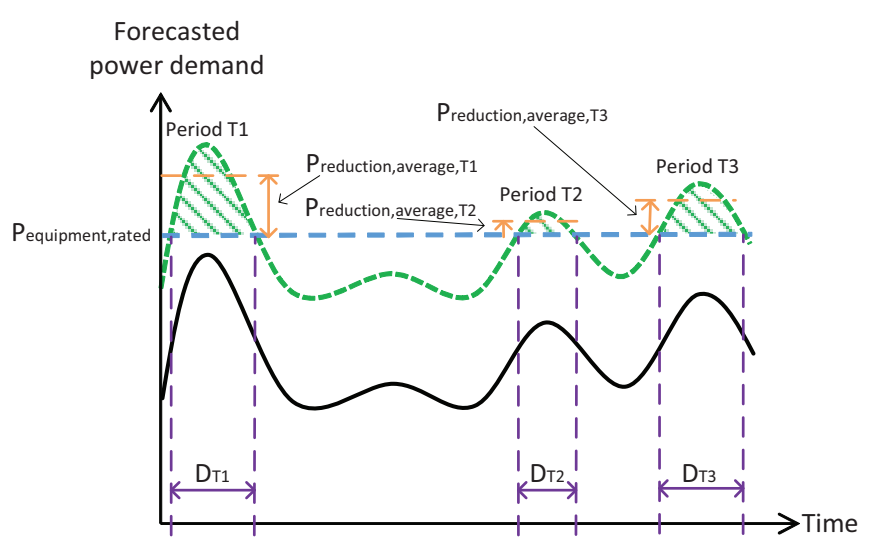

Fig. 3: Concept showing how to identify the periods for requesting flexibility services and amounts of power, that should be reduced. Black curve - forecasted electrical power flowing through component without HP connected; green dotted curve - new forecasted electrical power with connected HP

heat networks, this could be accomplished by optimizing the expenses of both DSO and DHO as shown in the following expression:

$$
\begin{array}{cl}
\min & C A P E X_{\text {total }}+O P E X_{\text {total }}, \\
\text { s.t. } & E q .4 \\
& E q .17 \\
& E q .18
\end{array}
$$

Constraints for this objective function are only reflecting the operational limitations for the heat and electrical networks, since it is assumed that other constraints such as heat source availability or the availability of the proper space for physical HP installation are already handled by assessing predefined locations.

Eq. 34 could be rewritten to include weighting factors:

$$
\begin{aligned}
\min & w_{e l} \cdot\left(C A P E X_{e l}+O P E X_{e l}\right) \\
+ & w_{\text {heat }} \cdot\left(C A P E X_{\text {heat }}+O P E X_{\text {heat }}\right),
\end{aligned}
$$

where $w_{e l}$ and $w_{\text {heat }}$ - weighting factors for electrical and heat utilities, respectively, $w \in\{0,1\}$.

Setting $w_{e l}=0$ and $w_{\text {heat }}=1$ will correspond to the conventional way of approaching the task of HP installation, when only expenses of DHO are taken into account. When both weighting factors equal to 1 , the expenses of both DHO and DSO are considered equally.

\section{CAse Study Description}

The case of installing a HP to supply heat demand of an urban district is considered in this paper. The city district of Nordhavn (Fig. 4), located in Copenhagen, Denmark is used as an example.

Three types of heat customers are considered: single houses, apartment blocks and office buildings. All of them are marked on Fig. 4 in bold font and will be referred to with both their 


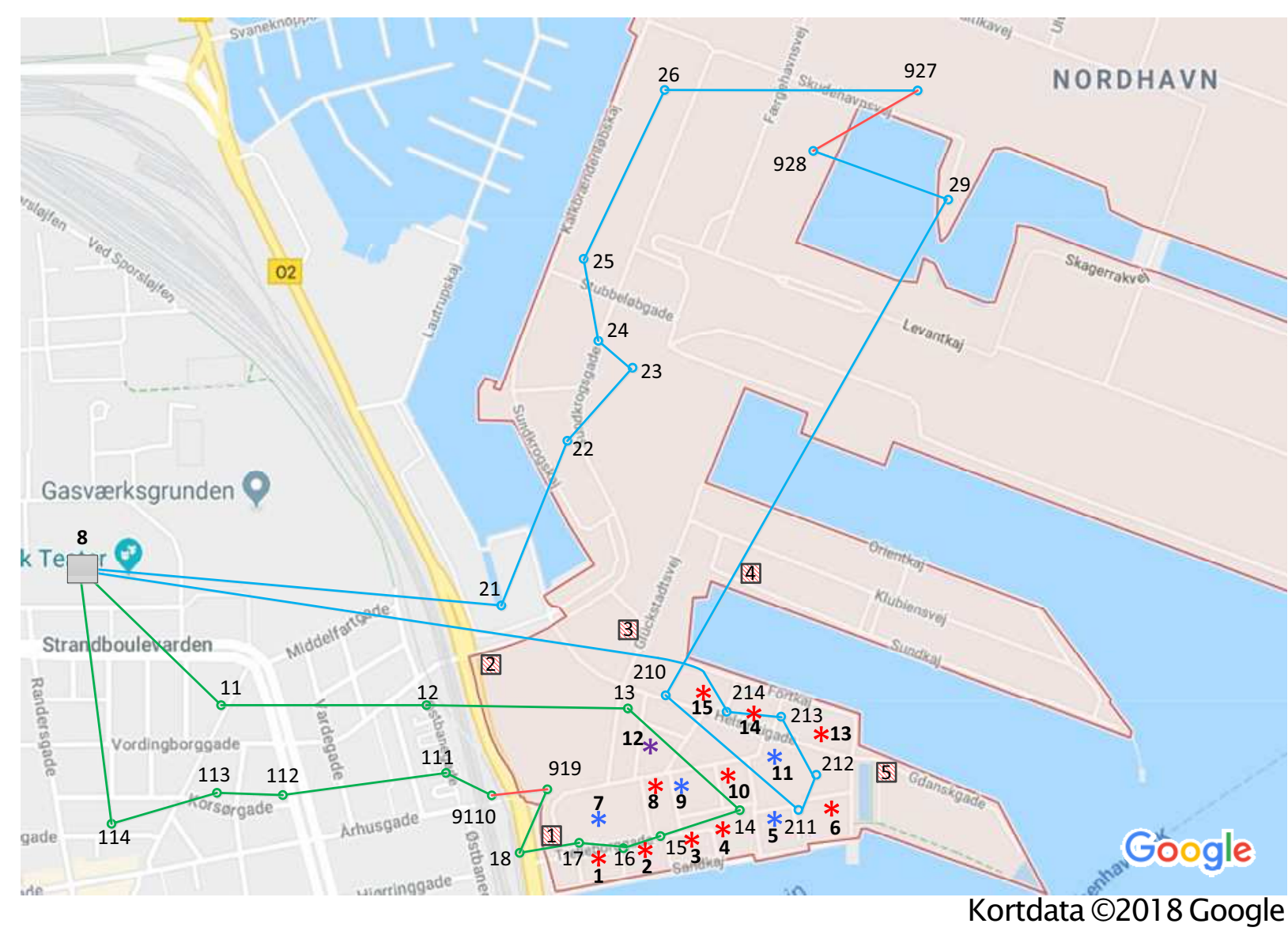

Fig. 4: Nordhavn city district. Electrical network: green and light blue lines - electrical distribution system layout (simplified), red lines - tie-lines between feeders; gray rectangle (8) - main substation, circles - secondary substations 10/0.4 kV. Heat network: the asterisk * - heat customer, purple * - group of single houses, red * - apartment block, blue * - office building; shaded square - possible location of HP

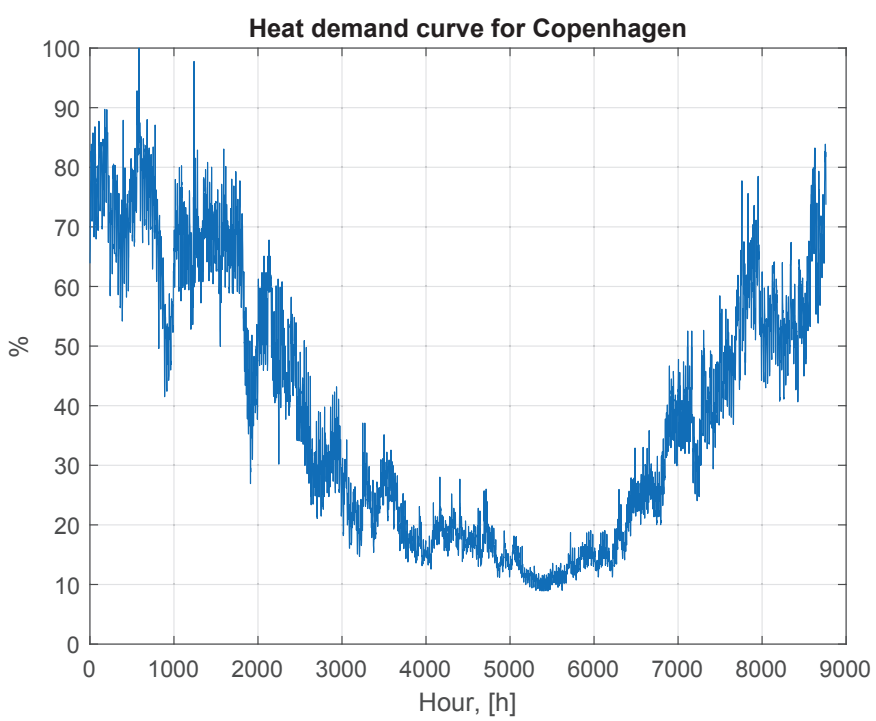

Fig. 5: General heat demand curve for Copenhagen number and asterisk symbol, i.e. $8^{*}$ or $11 *$. Single houses are grouped in a small block of 13 buildings, the rest of the district consists of 10 apartment blocks and 4 office multistorey office buildings. The sizes of these types of buildings are obtained from [14], [26]-[28]. The average size of single house is chosen to be $120 \mathrm{~m}^{2}$, apartment block $-3500 \mathrm{~m}^{2}$ and office building - $2400 \mathrm{~m}^{2}$.

The heat demand of each of the building is similar to the one shown on Fig 2 and represent the average monthly energy per $m^{2}$ needed to provide SP and DHW. In order to obtain the forecasted maximum peak demand, peak-to-average ratio $P T A$ is calculated from the heat demand curve on Fig. 5, which is based on a real data provided by DHO "HOFOR" [29] for Copenhagen area with hourly resolution.

5 possible locations have been chosen to install a HP. Location 2 will use groundwater as a heat source, while seawater will be used at locations 1, 3-5 due to the soil property in Nordhavn.

The considered DH operates with $80 / 45^{\circ} \mathrm{C}$ supply and return temperatures, respectively. Due to the changes in the temperature of the environment in the spring and summer months, the supply and return temperatures are also vary. This makes the average supply temperature $T_{\text {supply }}$ lower and 
TABLE I: Parameters for the case study

\begin{tabular}{|c|c|c|}
\hline Parameter & Value & Remarks \\
\hline$S_{1}-$ single house & $120\left[\mathrm{~m}^{2}\right]$ & [26] \\
\hline$S_{2}$ - apartment block & $3500\left[\mathrm{~m}^{2}\right]$ & [27|, |28 \\
\hline$S_{3}$ - office building & $2400\left[\mathrm{~m}^{2}\right]$ & [14] \\
\hline$N_{1}$ - single house & 13 & \\
\hline$N_{2}$ - apartment block & 10 & \\
\hline$N_{3}$ - office building & 4 & \\
\hline$D F$ & 0.7 & 30 \\
\hline PTA & $1.33-1.90$ & from $\mathrm{DHO}$ data \\
\hline$\Delta P r_{\max }$ & $100[\mathrm{~Pa} / \mathrm{m}]$ & |16] \\
\hline$c_{p}$ & $4200[\mathrm{~J} / \mathrm{kgK}]$ & \\
\hline$\rho$ & $971.8\left[\mathrm{~kg} / \mathrm{m}^{3}\right]$ & for water at $80{ }^{\circ} \mathrm{C}$ \\
\hline$T_{\text {supply }}$ & $75\left[{ }^{\circ} \mathrm{C}\right]$ & 31 \\
\hline$T_{\text {return }}$ & $47.5\left[{ }^{\circ} \mathrm{C}\right]$ & 31 \\
\hline$T_{\text {surround }}$ & $8\left[{ }^{\circ} \mathrm{C}\right]$ & [32] \\
\hline$h_{\text {heat }}$ & $8760[h]$ & from Fig. 5 \\
\hline$C O P_{\text {seawater,avg }}$ & 3.59 & [19] \\
\hline$C O P_{\text {groundwater,avg }}$ & 3.41 & 19 \\
\hline$P F$ & 0.95 lagging & 33] \\
\hline$R M$ & $15[\%]$ & \\
\hline$h_{e l}$ & $8760[h]$ & \\
\hline$P L$ & 20 [year $]$ & \\
\hline$r$ & $5[\%]$ & \\
\hline$C_{\text {el,price,HSO,avg,PL }}$ & $0.12[\$ / k W h]$ & |34| \\
\hline$C_{e l, p r i c e, D S O, \text { avg, } P L}$ & $0.10[\$ / k W h]$ & \\
\hline $\begin{array}{c}C_{\text {el, } \text {,inst }} \\
C_{\text {heat, }} \text { inst }\end{array}$ & $\begin{array}{l}10[\%] \\
10[\%]\end{array}$ & $\begin{array}{l}\text { of } C_{\text {cable,HP}}+C_{\text {additional }} \\
\text { of } C_{H P}+\sum C_{\text {nite }}\end{array}$ \\
\hline heat, & $10[10]$ & 年 \\
\hline
\end{tabular}

average return temperature $T_{\text {return }}$ higher than the nominal values. The number of heating hours $h_{\text {heat }}$ in a year were set to 8760 , since due to the DHW the heat demand still exists even during the summer months.

The electrical grid of Nordhavn is a $10 \mathrm{kV}$ medium voltage (MV) distribution grid. It is supplied from the main substation 30/10 kV (8 on Fig. 4) and consists of 4 feeders, connected in two loops. Feeders of each loop are connected to each other via a normally open tie-line. Each feeder has certain number of secondary substations $10 / 0.4 \mathrm{kV}$ that are used to supply customers. The power demand for these substations is a combination of different types of residential, commercial and light industrial demand based on the data from Nordhavn area. It is modeled as time-series load profiles with 1-hour resolution aggregated on the secondary substation level and is synthesized from the actual annual energy measurements of each customer obtained from electric utility and its historical power demand curve.

The values of the parameters used in calculations are shown in Table [

Three cases are considered: A). distribution network has enough electrical capacity for HP, so that HP can be connected to one of the loops; B). there is not enough electrical capacity to connect HP to one of the loops, so that HP should be connected via dedicated line to the main substation; C). flexibility from HP is used to solve the electrical capacity problem and avoid building a dedicated connection.

\section{Results}

The peak heat demand $Q_{\text {heat,peak }}$ for the DH network is 1.6260 $M W$, with $4872.1 M W h$ of annual energy $E_{\text {heat,year }}$, that has to be provided for heating purposes.

Based on the volumes of water flow required to supply individual buildings, 4 types of heat pipes are selected for
TABLE II: Nominal pipe sizes

\begin{tabular}{c|c|c} 
Pipe nominal size & $d_{\text {pipe }},[\mathrm{m}]$ & $C_{\text {pipe }},[\$ / \mathrm{m}]$ \\
\hline DN 50 & 0.0530 & 261 \\
DN 90 & 0.0960 & 472 \\
DN 125 & 0.1280 & 629 \\
DN 150 & 0.1540 & 757
\end{tabular}

TABLE III: Total length, average pipe diameter and total cost of DH network for different HP locations

\begin{tabular}{c|c|c|c} 
Location & $L_{\text {pipe }},[\mathrm{m}]$ & $D_{a},[\mathrm{~m}]$ & $\sum C_{\text {pipe, } t,},[\mathrm{k} \$]$ \\
\hline 1 & 1240 & 0.1062 & 364.8 \\
2 & 1424 & 0.0969 & 410.6 \\
3 & 1511 & 0.0938 & 427.8 \\
4 & 1354 & 0.0933 & 359.1 \\
5 & 1310 & 0.0938 & 363.1
\end{tabular}

the DH design with their parameters shown in Table II The cost of the pipes is estimated from [35]. The pipes are chosen, so that they can supply the necessary volume of water for 1 , 4, 8 and all buildings respectively.

The optimal DH network design is performed, where both pipe sizes and network length are minimized. The total length $L_{\text {pipe }}$ and cost of DH network $\sum C_{\text {pipe } f t}$ for each of the HP locations are given in Table III. The corresponding yearly heat losses $E_{\text {heat,loss,year }}$ and relative losses $q_{\text {loss,relative }}$ are shown in Table IV]

Table $[\mathrm{V}$ shows the required and rated electrical capacity for the HP depending on the heat source at different locations. Since the difference in power is relatively small, the rated power is the same for all locations. The cost of electrical cable to connect the HP to $10 \mathrm{kV}$ network is estimated to be: 200 $\$ / m$.

\section{A. Case A}

If the feeders in the distribution network have enough capacity, the HP can be connected to one of the loops. The additional $\operatorname{cost} C_{\text {additional }}$ in this case is the cost of an additional transformer that will be placed at one of the already existed substations. Using $P_{H P}$ and calculating apparent power $S_{H P}$, $630 \mathrm{kVA} 10 / 0.4 \mathrm{kV}$ three-phase transformer was estimated to be enough to connect HP to the electrical network. The cost of the transformer is estimated to be $20000 \$$. $C_{\text {additional }}$ for substations 14,17 and 21 is equal to zero, since the transformers on these substations have enough spare capacity to connect HP.

TABLE IV: Yearly and relative heat losses

\begin{tabular}{c|c|c} 
Location & $E_{\text {heat,loss,year },[M W h]}$ & qloss,relative, $[\%][\mathrm{M}$ \\
\hline 1 & 170.13 & 3.37 \\
2 & 188.73 & 3.73 \\
3 & 197.69 & 3.90 \\
4 & 171.42 & 3.40 \\
5 & 171.35 & 3.40
\end{tabular}

TABLE V: Electrical capacity and cost of HP unit

\begin{tabular}{c|c|c|c|c} 
Location & $P_{H P},[k W]$ & $P_{H P, r a t e d},[k W]$ & Heat source & $C_{H P},[k \$]$ \\
\hline 1 & 468.2 & 500 & Seawater & 50 \\
2 & 494.6 & 500 & Groundwater & 80 \\
3 & 470.6 & 500 & Seawater & 50 \\
4 & 468.3 & 500 & Seawater & 50 \\
5 & 468.3 & 500 & Seawater & 50
\end{tabular}


TABLE VI: Case A

\begin{tabular}{c|c|c|c|c|c} 
Location & $\begin{array}{c}C A P E X_{\text {heat }}, \\
{[k \$]}\end{array}$ & $\begin{array}{c}O P E X_{\text {heat }}, \\
{[k \$]}\end{array}$ & $\mathbf{P C}$ & $\begin{array}{c}C A P E X_{\text {el }}, \\
{[k \$]}\end{array}$ & $\begin{array}{c}\text { OPEX } \\
{[k \$]}\end{array}$ \\
\hline 1 & 456.3 & 2135.4 & 16 & 25.7 & 10.5 \\
2 & 539.7 & 2256.4 & 21 & 19.9 & 5.4 \\
3 & 525.5 & 2147.1 & 21 & 46.8 & 5.2 \\
4 & 450.0 & 2136.0 & 214 & 68.8 & 4.5 \\
5 & 454.4 & 2135.9 & 212 & 45.1 & 4.8
\end{tabular}

TABLE VII: Case B

\begin{tabular}{c|c|c|c|c|c} 
Location & $\begin{array}{c}C A P E X_{\text {heat }}, \\
{[k \$]}\end{array}$ & $\begin{array}{c}\text { OPEX } \\
{[k \$]}\end{array}$ & $\mathbf{P C}$ & $\begin{array}{c}C A P E X_{\text {el }}, \\
{[k \$]}\end{array}$ & $\begin{array}{c}O P E X_{e l}, \\
{[k \$]}\end{array}$ \\
\hline 1 & 456.3 & 2135.4 & 8 & 202.5 & 0.89 \\
2 & 539.7 & 2256.4 & 8 & 162.9 & 0.78 \\
3 & 525.5 & 2147.1 & 8 & 209.9 & 0.93 \\
4 & 450.0 & 2136.0 & 8 & 247.5 & 1.10 \\
5 & 454.4 & 2135.9 & 8 & 301.06 & 1.35
\end{tabular}

The power flow analysis using software package for Matlab MATPOWER [36] is performed for all the potential points of connection (PC) in order to check the constraints of Eq. 17 and 18 It is assumed that the power demand curve for HP has the same shape as the one on Fig. 5

The individual CAPEX and OPEX for DSO and DHO are shown in Table VI From DHO perspective, it is better to install HP in Location 4, while DSO preferred Location 2. OPEX $X_{\text {heat }}$ dominates the expenses due to the fact, that it includes the cost of total energy bought from DSO, while $O P E X_{e l}$ only includes the cost of additional electrical losses caused in the system by the connection of HP.

The total combined cost of both utilities together are summarized in Table IX and shown that when the interests of both parties are taken into account, the optimal HP location shifts to Location 1.

\section{B. Case B}

If the distribution feeders do not have enough electrical capacity to accommodate the connection of HP, they have to be reinforced, i.e. changed to the ones with higher capacity. Since the total cables length and the amount of engineering work could be quite significant, an alternative - to supply HP through a dedicated line from the main substation could be preferred. This will increase the total cost for the DSO as compared to Case A as could be seen from Table VII

Since now the HP is electrically closer to the source of electrical power, the electrical losses are lower than in Case A. Similar to the previous case, the optimal location is shifted from the one preferred by DHO alone as follows from the total costs in Table IX

\section{Case C}

In some cases, the flexibility services from HP such as peak reduction or load shifting can be used to connect it to the distribution feeders without the need for reinforcement. It is dependant on the amount of power that has to be reduced from the HP side and the duration of the reduction.

In the current example, the calculations were made in order to reduce the peak electrical power of HP by $10 \%$, which will allow to connect the HP to one of the feeders. If the HP power
TABLE VIII: Case C

\begin{tabular}{c|c|c|c|c|c} 
Location & $\begin{array}{c}C A P E X_{\text {heat }}, \\
{[k \$]}\end{array}$ & $\begin{array}{c}\text { OPEX } \\
{[k \$]}\end{array}$ & PC & $\begin{array}{c}C A P E X_{\text {el }}, \\
{[k \$]}\end{array}$ & $\begin{array}{c}\text { OPEX } \\
{[k \$]}\end{array}$ \\
\hline 1 & 456.3 & 2135.4 & 16 & 25.7 & 47.0 \\
2 & 539.7 & 2256.4 & 21 & 19.9 & 38.1 \\
3 & 525.5 & 2147.1 & 21 & 46.8 & 36.4 \\
4 & 450.0 & 2136.0 & 214 & 68.8 & 34.9 \\
5 & 454.4 & 2135.9 & 212 & 45.1 & 35.6
\end{tabular}

TABLE IX: Total combined cost of DSO and DHO for the different HP locations

\begin{tabular}{c|c|c|c}
\multirow{2}{*}{ Location } & Case A & Case B & Case C \\
\cline { 2 - 4 } & Total, $[k \$]$ & Total, $[k \$]$ & Total, $[k \$]$ \\
\hline 1 & 2627.9 & 2795.1 & 2664.4 \\
2 & 2821.4 & 2959.8 & 2854.1 \\
3 & 2724.6 & 2883.5 & 2755.9 \\
4 & 2659.3 & 2834.6 & 2689.7 \\
5 & 2640.2 & 2892.7 & 2671.0
\end{tabular}

demand throughout the year is following the same shape as a curve on Fig. 5, flexibility services from HP should only be called 9 hours per year, making 3 periods of 3,4 and 2 hours in duration, respectively. The first two periods occur around morning peak hours from 06:00 to 09:00 [37] and the last one is in the off-peak period. The price for providing flexibility is assumed to be $10 \$ / k W h$ for the morning peak period and 7 $\$ / k W h$ plus additional $100 \$$ as $C_{\text {frequency }}$.

CAPEX and OPEX for Case $\mathrm{C}$ are given in Table VIII The combined cost are shown in Table IX]

Use of flexibility services allows to connect HP to the one of the already existing substation, which is located close to the HP installation site, thus significantly lowering $C A P E X_{e l}$ as opposed to Case B. From the other hand, $O P E X_{e l}$ will increase, because of the price for flexibility services.

\section{Conclusions}

The methodology for integrated planning for a large HP in the heat and electrical networks is presented in this paper. It was shown that by considering the interests of both stakeholders (DSO and DHO), the optimal installation location for HP is shifted from the one that would be preferred by DHO alone. The new location will provide a higher societal benefit - the reduced total cost and allows to better utilize the synergy between heat and power sectors via flexibility services. The optimal HP location is highly dependent on the costs associated with each stakeholder, the availability of the heat sources and spare capacity of the electrical network and has to be analysed on a case-by-case basis.

\section{ACKNOWLEDGMENT}

This work was supported by the Danish Energy Development Programme (EUDP) through the EnergyLab Nordhavn (Grant : EUDP 64015-0055).

\section{REFERENCES}

[1] C. Shao, Y. Ding, J. Wang, and Y. Song, "Modeling and integration of flexible demand in heat and electricity integrated energy system," IEEE Transactions on Sustainable Energy, vol. 9, no. 1, pp. 361-370, 2018. 
[2] S. You, L. Jin, J. Hu, Y. Zong, and H. W. Bindner, "The danish perspective of energy internet: from service-oriented flexibility trading to integrated design, planning and operation of multiple cross-sectoral energy systems," Zhongguo Dianji Gongcheng Xuebao, vol. 35, no. 14, pp. 3470-3481, 2015.

[3] X. Zhang, M. Shahidehpour, A. Alabdulwahab, and A. Abusorrah, "Optimal expansion planning of energy hub with multiple energy infrastructures," IEEE Transactions on Smart Grid, vol. 6, no. 5, pp. 2302-2311, 2015.

[4] S. Pazouki and M.-R. Haghifam, "Optimal planning and scheduling of energy hub in presence of wind, storage and demand response under uncertainty," International Journal of Electrical Power $\mathcal{E}$ Energy Systems, vol. 80, pp. 219-239, 2016.

[5] H. Ü. Yilmaz, D. Keles, A. Chiodi, R. Hartel, and M. Mikulić, "Analysis of the power-to-heat potential in the european energy system," Energy Strategy Reviews, vol. 20, pp. 6-19, 2018.

[6] H. Lund, S. Werner, R. Wiltshire, S. Svendsen, J. E. Thorsen, F. Hvelplund, and B. V. Mathiesen, "4th generation district heating (4gdh): Integrating smart thermal grids into future sustainable energy systems," Energy, vol. 68, pp. 1-11, 2014.

[7] F. Levihn, "Chp and heat pumps to balance renewable power production: Lessons from the district heating network in stockholm," Energy, vol. 137, pp. 670-678, 2017.

[8] H. Schermeyer, C. Vergara, and W. Fichtner, "Renewable energy curtailment: A case study on today's and tomorrow's congestion management," Energy Policy, vol. 112, pp. 427-436, 2018.

[9] H. Cai, S. You, J. Wang, H. W. Bindner, and S. Klyapovskiy, "Technical assessment of electric heat boosters in low-temperature district heating based on combined heat and power analysis," Energy, 2018.

[10] A. David, B. V. Mathiesen, H. Averfalk, S. Werner, and H. Lund, "Heat roadmap europe: Large-scale electric heat pumps in district heating systems," Energies, vol. 10, no. 4, p. 578, 2017.

[11] B. Elmegaard, F. Bühler, J. K. Jensen, P. H. Jørgensen, R. Mancini, W. B. Markussen, W. Meesenburg, T. Ommen, H. Pieper, E. Rothuizen et al., "Heat pumps for efficient and flexible heat supply in copenhagen," in Sustain 2017. Technical University of Denmark (DTU), 2017.

[12] Denmark funds heat pumps for district heating. [Online]. Available: http://www.decentralized-energy.com/articles/2018/01/ denmark-funds-heat-pumps-for-district-heating.html

[13] S. Klyapovskiy, S. You, H. W. Bindner, and H. Cai, "Optimal placement of a heat pump in an integrated power and heat energy system," in Green Technologies Conference (GreenTech), 2017 Ninth Annual IEEE. IEEE, 2017, pp. 246-253.

[14] P. Zangheri, R. Armani, M. Pietrobon, L. Pagliano, M. F. Boneta, and A. Müller, "Heating and cooling energy demand and loads for building types in different countries of the eu," Polytechnic University of Turin, end-use Efficiency Research Group, vol. 3, 2014.

[15] A. Heller, Demand modelling for central heating systems. Department of Buildings and Energy, Technical University of Denmark, 2000.

[16] Een-e3004 - district heating and cooling course. aalto university. [Online]. Available: https://mycourses.aalto.fi/pluginfile.php/612531/ mod_resource/content/1/DHC04_Distribution.pdf

[17] V. Masatin, E. Latõšev, and A. Volkova, "Evaluation factor for district heating network heat loss with respect to network geometry," Energy Procedia, vol. 95, pp. 279-285, 2016.

[18] D. Lauka, J. Gusca, and D. Blumberga, "Heat pumps integration trends in district heating networks of the baltic states," Procedia Computer Science, vol. 52, pp. 835-842, 2015.

[19] H. Pieper, T. Ommen, W. Markussen, and B. Elmegaard, "Optimal usage of low temperature heat sources to supply district heating by heat pumps," in 30th International Conference on Efficiency, Cost, Optimization, Simulation and Environmental Impact of Energy SystemsInternational Conference on Efficiency, Cost, Optimization, Simulation and Environmental Impact of Energy Systems, 2017.

[20] H. Saadat, Power system analysis. McGraw-Hill, 1999.

[21] F. Iov, A. D. Hansen, P. Sørensen, and N. A. Cutululis, "Mapping of grid faults and grid codes," Technical University of Denmark, Vol: Ris $\phi$, 2007.

[22] S. Klyapovskiy, S. You, R. C. Domens, H. Cai, and H. W. Bindner, "Deferral of grid reinforcement by using dual flexibility options enabled by a grid-connected heat pump," in Accepted for publication at 2018 IEEE PES Transmission and Distribution Conference and Exposition, 2017.

[23] H. Benli, "Energetic performance analysis of a ground-source heat pump system with latent heat storage for a greenhouse heating," Energy conversion and management, vol. 52, no. 1, pp. 581-589, 2011.
[24] S. A. Kyriakis and P. L. Younger, "Towards the increased utilisation of geothermal energy in a district heating network through the use of a heat storage," Applied Thermal Engineering, vol. 94, pp. 99-110, 2016.

[25] E. Trømborg, M. Havskjold, T. F. Bolkesjø, J. G. Kirkerud, and ̊. G. Tveten, "Flexible use of electricity in heat-only district heating plants," International Journal of Sustainable Energy Planning and Management, vol. 12, pp. 29-46, 2017.

[26] The environmental change institute. [Online]. Available: http://www.eci. ox.ac.uk/research/energy/downloads/countrypictures/cp denmark.pdf

[27] Eu building database. [Online]. Available: https://ec.europa.eu/energy/ en/eu-buildings-database

[28] M. Harrestrup and S. Svendsen, "Changes in heat load profile of typical danish multi-storey buildings when energy-renovated and supplied with low-temperature district heating," International Journal of Sustainable Energy, vol. 34, no. 3-4, pp. 232-247, 2015.

[29] Hofor. [Online]. Available: https://www.hofor.dk/privat/

[30] District heating \& heat network design. [Online]. Available: http: //www.usewoodfuel.co.uk/media/411085/k. boyle-district heating and_heat_network_design_bridge_of_allan_11_mar_2014.pdf

[31] D. Culig-̄̄okić, G. Krajačić, B. Doračić, B. V. Mathiesen, R. Krklec, and J. M. Larsen, "Comparative analysis of the district heating systems of two towns in croatia and denmark," Energy, vol. 92, pp. 435-443, 2015.

[32] D. Banks, An introduction to thermogeology: ground source heating and cooling. John Wiley \& Sons, 2012

[33] M. Akmal, B. Fox, J. D. Morrow, and T. Littler, "Impact of heat pump load on distribution networks," IET Generation, Transmission $\mathcal{E}$ Distribution, vol. 8, no. 12, pp. 2065-2073, 2014.

[34] O. Gudmundsson, J. Thorsen, and L. Zhang, "Cost analysis of district heating compared to its competing technologies," WIT Transactions on Ecology and the Environment, vol. 176, pp. 3-13, 2013.

[35] C. H. Christiansen, A. Dalla Rosa, M. Brand, P. K. Olsen, and J. E. Thorsen, "Results and experiences from a 2-year study with measurements on a new low-temperature district heating system for low-energy buildings," in The 13th International Symposium on District Heating and Cooling, Copenhagen, 2012.

[36] R. D. Zimmerman, C. E. Murillo-Sánchez, and R. J. Thomas, "Matpower: Steady-state operations, planning, and analysis tools for power systems research and education," IEEE Transactions on power systems, vol. 26 , no. 1, pp. 12-19, 2011.

[37] J. Torriti, "Understanding the timing of energy demand through time use data: Time of the day dependence of social practices," Energy research $\mathcal{E}$ social science, vol. 25 , pp. 37-47, 2017. 